\title{
On the response of the tropical atmosphere to large-scale deforestation
}

\author{
By E. A. B. ELTAHIR and R. L. BRAS* \\ Massachusetts Institute of Technology, USA
}

(Reccived 13 July 1992; revised 16 November 1992)

\section{SUMMARY}

Recent studies on the Amazon deforestation problem predict that removal of the forest will result in a higher surface temperature, a significant reduction in evaporation and precipitation, and possibly significant changes in the tropical circulation. Here, we discuss the basic mechanisms contributing to the response of the tropical atmosphere to deforestation. A simple linear model of the tropical atmosphere is used in studying the effects of deforestation on climate. It is suggested that the impact of large-scale deforestation on the circulation of the tropical atmosphere consists of two components: the response of the tropical circulation to the negative change in precipitation (heating), and the response of the same circulation to the positive change in surface temperature. Owing to their different signs, the changes in predicted temperature and precipitation excite competing responses working in opposite directions.

The predicted change in tropical circulation determines the change, if any, in atmospheric moisture convergence, which is equivalent to the change in run-off. The dependence of run-off predictions on the relative magnitudes of the predicted changes in precipitation and surface temperature implies that the predictions about run-off are highly sensitive, which explains, at least partly, the disagreement between the different models concerning the sign of the predicted change in Amazonian run-off.

\section{INTRODUCTION}

Deforestation of tropical rain forests is occurring at alarming rates. A recent study estimates that the area of the world's largest rain forest of the Amazon is shrinking at a rate of 20000 square kilometres per year (Nobre et al. 1991). Large-scale removal of the rain forest will have significant effects on the natural environment. The impact of deforestation goes beyond the elimination of species and erosion of the soil, to the possibility of adverse effects on the regional and global climate.

Recent studies by Dickinson and Henderson-Sellers (1988), Lean and Warrilow (1989) and Nobre et al. (1991), focus on the possible impacts on the regional climate due to large-scale deforestation in the Amazon region, and in studying the possible effects of deforestation on climate they all use general circulation models (GCMs). Owing to the nature of the deforestation problem it is important to include realistic descriptions of the physical processes at the land surface; the studies mentioned above include stateof-the-art descriptions of land-surface processes. In these three studies there is agreement regarding the prediction that large-scale deforestation of the total area of the Amazon forest will probably result in regional climatic changes such as less evaporation, higher surface temperatures and less precipitation, but there is disagreement about the magnitudes of these changes; however there is agreement about the sign of the change. The predictions of annual values resulting from these three studies, averaged over large deforested areas which, roughly, correspond to the Amazon basin, are given in Table 1 . In Fig. 1 is shown the spatial distribution of the changes predicted by the recent study of Nobre et al. (1991).

The results of the same deforestation studies predict significant changes in run-off, defined as the difference between precipitation and evaporation. Although in their studies Nobre et al. (1991) and Lean and Warrilow (1989) agree in predicting a reduction in runoff, Dickinson and Henderson-Sellers (1988) predict a significant increase in run-off. Part of the increase in surface run-off predicted by Dickinson and Henderson-Sellers

* Corresponding author: Ralph M. Parsons Laboratory, Massarhusetts Institute of Technology, Cambridge, MA 02139, USA. 
TABlE 1. Predictions of the SPATIAlly aVERAGed Regional Changes in Key ATMOSPHERIC VARIABLES DUE TO DEFORESTATION OF THE AMAZON RAIN FOREST

\begin{tabular}{lccc}
\hline & $\begin{array}{c}\text { Dickinson and } \\
\text { Henderson-Sellers } \\
(1988)\end{array}$ & $\begin{array}{c}\text { Lean and } \\
\text { Warrilow } \\
(1989)\end{array}$ & $\begin{array}{c}\text { Nobre } \\
\text { et al. } \\
(1991)\end{array}$ \\
\hline Temperature $\left({ }^{\circ} \mathrm{C}\right)$ & +1.5 & +2.4 & +2.5 \\
Precipitation (mm d $)$ & -0.27 & -1.34 & -1.76 \\
Precipitation (\%) & -3 & -20 & -25 \\
Evaporation (\%) & -8 & -27 & -30 \\
Run-off (\%) & +6 & -12 & -18 \\
(precipitation - evaporation) & & & \\
\hline
\end{tabular}
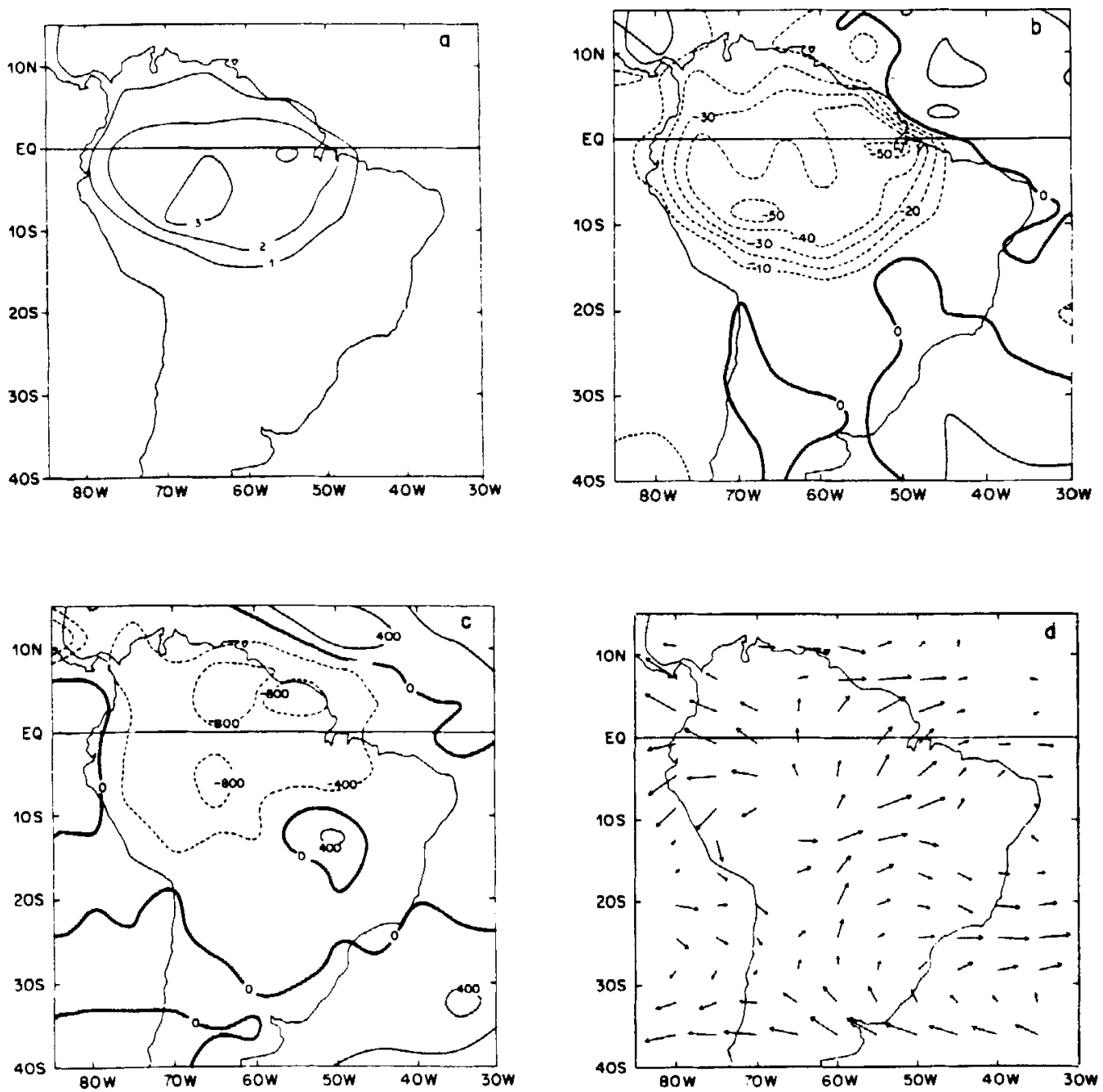

Figure 1. Predictions of the regional climatic change due to deforestation of the Amazon rain forest, Nobre et al. (1991). (a) Temperature change $\left({ }^{\circ} \mathrm{C}\right)$. (b) Evaporation change $\left(\mathrm{W} \mathrm{m}^{-2}\right)$. (c) Precipitation change (mm).

(d) Change in the wind vector at $700 \mathrm{mb}$. 
(1988) is due to change in soil moisture but, as seen from Table 1, a small part of this is due to the increase in atmospheric moisture convergence. Nobre et al. argue that additional experiments are needed to explain their predictions about moisture convergence and run-off. Lean and Warrilow deduce that the reduction in moisture flux convergence is due mainly to the increased surface albedo as opposed to the change in roughness. In the following we present a different perspective on the basic processes that contribute to a change in tropical circulation and, hence, dictate the possible changes in moisture flux convergence. We emphasize the effects on the dynamics of the tropical atmosphere of the predicted changes in precipitation and surface temperature.

A decrease in precipitation is equivalent to a negative anomaly in heating of the upper troposphere; the dynamics of the tropical atmosphere is sensitive to localized heating. The magnitude of the change (about $20 \%$ ) in precipitation and its large spatial extent suggest that the heating anomaly due to deforestation is likely to excite a significant response in the tropical atmosphere. Another important prediction is the change in surface temperature; in the absence of other factors a positive surface temperature anomaly reduces surface pressure, and results in a circulation converging towards the Amazon. We suggest that the response of the tropical atmosphere to large-scale deforestation is forced, mainly by the anomalies in heating and surface temperature. Our objective is to determine the relative contributions of these two processes-at least their orders of magnitude. The resulting change in the tropical circulation will determine whether moisture convergence into the Amazon basin will increase or decrease as a result of deforestation. The significance of this question stems from the fact that atmospheric moisture convergence into the Amazon basin is equivalent to run-off from the world's largest river.

A simplified linear model of the tropical atmosphere, similar to that of Gill (1980), will be used in studying the response of the atmosphere to deforestation. This model was developed to describe the Walker circulation as a response of the tropical atmosphere to localized heating. The same model was later used by Zebiak (1982) in studying the El Niño phemomenon, particularly in simulating the response of the tropical atmosphere to the heating anomalies associated with it. Success from using the model in reproducing some of the circulation anomalies observed during El Niño events suggests that the model includes the processes necessary for describing the response of the tropical atmosphere to the prescribed forcing. Furthermore, the simple structure of the model might provide a useful insight into the basic mechanisms contributing to the response of the tropical atmosphere to deforestation.

In the following, some of the effects of deforestation on climate will be reviewed. The links between deforestation and the predictions given in Table 1 will be discussed. A simple linear model of the tropical atmosphere is described and then applied to the deforestation problem in the Amazon basin, using the forcing predicted by the GCM experiments. The sensitivity of Amazonian run-off to large-scale deforestation is studied.

\section{EFFECTS OF DEFORESTATION ON CLIMATE}

Deforestation results directly in some important effects on climate. Removal of the rain forest eliminates some of the biomass that absorbs most of the solar radiation incident on the surface. Less biomass results in less absorption and more reflection of solar radiation, hence a higher surface albedo. A higher surface albedo, everything else being equal, results in there being less energy available for evaporation from the surface. Replacement of the forest with a shorter vegetational cover reduces the roughness of the surface layer and causes reduction of the eddy transport of water vapour, heat and 
momentum near the surface; a shorter roughness length also results in less evaporation and higher surface temperatures. Another factor which can affect evaporation is reduction in leaf area; a smaller leaf area implies a reduced area active in transpiration and in canopy storage available for interception. Deforestation also has a direct effect on the top soil layer, which becomes more exposed to erosion and so contains a shallower rooting zone. The top soil layer controls surface run-off and stores the moisture necessary for transpiration; hence changes to the top soil layer affect these two processes.

The most important feedbacks which could result from tropical deforestation are the possible effects on the rainfall-producing mechanisms. Deforestation of small areas (e.g. tens of kilometres each side) changes the spatial distribution of sensible and latent heat fluxes. The resulting heterogeneity in the surface temperature and humidity fields plays a significant role in the initiation of convection and could favour mesoscale circulations, so producing more rainfall. On the other hand deforestation of large areas (e.g. thousands of kilometres each side) reduces evaporation and results in a drier boundary layer which, in turn, affects precipitation significantly because not only is less water available to form clouds but, even more important, there is a reduction in energy available for convection. A reduction of rainfall over the deforested area is, necessarily, accompanied by reduced cloudiness and, for that reason, a lower planetary albedo. The reduction in albedo due to the change in cloudiness can be large enough to offset the direct effect of increased surface albedo.

The results presented in Table 1 may be interpreted as follows. The three studies indicate that deforestation of the Amazon basin will probably result in less evaporation and precipitation. The reduction in evaporation is due largely to the shorter roughness length, while the reduction of precipitation is due mainly to the smaller amount of energy available for convection following deforestation. Since evaporation cools the surface, the reduction in evaporation results in an increase in surface temperature. The predicted changes in precipitation and surface temperature can be used as input to a linear model of the tropical atmosphere for studying its response to deforestation, particularly to changes of run-off.

\section{A SIMPLE MODEL OF THE TROPICAL ATMOSPHERE}

The original version of the model used here was first introduced by Matsuno (1966), and was developed further by Gill (1980) who used it to describe the tropical circulations induced by latent heat release. We agree with the suggestion of Neelin (1988) that the Gill model is basically a model of the boundary-layer flow. The horizontal momentum equations are expressed approximately by

$$
\begin{array}{r}
f v^{\prime}-\partial_{x} \Phi^{\prime}-\varepsilon u^{\prime}=0 \\
-f u^{\prime}-\partial_{y} \Phi^{\prime}-\varepsilon v^{\prime}=0 .
\end{array}
$$

The variables and parameters in the above equations are defined as follows: $u^{\prime}$ and $v^{\prime}$ are perturbations in the horizontal components of mass flux in the boundary layer, $\Phi^{\prime}$ is the mass-weighed integral of the perturbation in geopotential height in the boundary layer, $\varepsilon$ is the coefficient of Rayleigh friction, $f$ is the Coriolis parameter.

The three terms in each of the above equations represent the equilibrium between the Coriolis force, the pressure gradient force and the momentum dissipation. Since we 
are only interested in equilibrium solutions, the time-derivative terms are taken to be zero and, because the two equations are linearized about a basic state of no motion, the advective terms also are assumed to be zero; the implications of this assumption are discussed later.

Continuity of flow in the boundary layer can be described in pressure coordinates by the equation

$$
\partial_{x} u^{\prime}+\partial_{y} v^{\prime}+\frac{w^{\prime}}{g}=0
$$

where $w^{\prime}$ is the perturbation to the vertical velocity field above the boundary layer and $g$ is the gravitational acceleration.

In deriving the energy equation, it is supposed that energy balance in the tropics is mainly between diabatic processes (latent heat release and radiation) and adiabatic heating induced by vertical motion. This supposition is justified by the observation that temperature gradients are very small in the tropics and hence, also, are the effects of heat advection. In representing the radiation effect it is supposed that temperature perturbations are equivalent to pressure perturbations, and that the coefficient of Newtonian cooling is equivalent to the coefficient of Rayleigh friction. This supposition is the least credible in the model but, as shown by Neelin (1988), the model results are not sensitive to this supposition, unless the model is used for describing the total climatological circulation. A simplified form of the energy equation is then given by

$$
\frac{w^{\prime}}{g}=\frac{\left(\varepsilon \Phi^{\prime}+a P^{\prime}\right)}{c^{2}}
$$

The variables and parameters in the above equation are defined as follows: $P^{\prime}$ is the perturbation to the precipitation field; $a$ is a constant defined as $a=L R \Delta p /\left(2 p c_{p}\right)$, where $L$ is the latent heat of condensation, $R$ is the gas constant for dry air, $c_{p}$ is the specific heat capacity of dry air at constant pressure, $\Delta p$ is half the depth of the troposphere corresponding to the region heated by condensation of water vapour and $p$ is a mid-level tropospheric pressure (about $500 \mathrm{mb}$ ); $c$ is the wave speed defined as $c^{2}=S R \Delta p^{2} / 2 p$, where $S$ is static stability (taken in this paper to be $S=4.2 \times 10^{-5} \mathrm{~m} \mathrm{~K} \mathrm{~s}^{2} /$ $\mathrm{kg}$ ). The two terms on the right-hand side of Eq. 4 represent the contributions of radiation and latent heat release. For details of the derivation of Eq. 4 we refer to Neelin (1988).

Equations (3) and (4) are now combined to form the equation

$$
\varepsilon \Phi^{\prime}+c^{2}\left(\partial_{x} u^{\prime}+\partial_{y} v^{\prime}\right)=-a P^{\prime}
$$

Equations (1), (2) and (5) provide a closed set involving the three variables $u^{\prime}, v^{\prime}$ and $\Phi^{\prime}$; the forcing is given by the latent heat release, which is proportional to $P^{\prime}$. Gill (1980) used a similar set of equations to study the response of the tropical atmosphere to localized heating.

Lindzen and Nigam (1987) studied the role of sea-surface-temperature gradients in forcing low-level winds and convergence in the tropics; they developed a simple model of the trade-cumulus boundary layer. It was found that the flow resulting from forcing the model by observed surface temperatures is comparable to observed low-level flows. Neelin (1989) transformed the Lindzen-Nigam model into a form similar to the Gill model, the forcing being given by an anomaly in surface temperature instead of in precipitation. By using this transformation the Lindzen-Nigam model can be described 
by the following set of equations,

$$
\begin{gathered}
f v^{\prime}-\partial_{x} \Phi^{\prime \prime}-\varepsilon u^{\prime}=0 \\
-f u^{\prime}-\partial_{y} \Phi^{\prime \prime}-\varepsilon v^{\prime}=0 \\
\varepsilon \Phi^{\prime \prime}+c^{2}\left(\partial_{x} u^{\prime}+\partial_{y} v^{\prime}\right)=-b T_{\mathrm{s}}^{\prime}
\end{gathered}
$$

which are similar to Eqs. (1), (2) and (5), but with the precipitation forcing replaced by the surface-temperature forcing. The variables and parameters in the above equations are defined as follows: $T_{s}^{\prime}$ is the perturbation in surface temperature; $b=\varepsilon \delta p H_{0} / 2 T_{0}$, where $\delta p$ is the depth of the boundary layer in units of pressure, $H_{0}$ is the depth of the boundary layer in units of length and $T_{0}$ is a constant reference temperature $\left(T_{0}=288 \mathrm{~K}\right.$, Lindzen and Nigam 1987); $\Phi^{\prime \prime}=g\left(h^{\prime}-H_{0} / 2 T_{0}\right) T_{\mathrm{s}}{ }^{\prime}$, where $h^{\prime}$ is the perturbation to the height of the boundary layer.

In the deforestation problem we are interested in the response of the atmosphere to anomalies in both precipitation and surface temperature. Since the set of equations $(1),(2)$, and (5) and the set $(6 \mathrm{a}-\mathrm{c})$ are linear, we add the corresponding equations in each set together to form the following set:

$$
\begin{gathered}
f v^{\prime}-\partial_{x} \Phi^{\prime \prime}-\varepsilon u^{\prime}=0 \\
-f u^{\prime}-\partial_{y} \Phi^{\prime \prime \prime}-\varepsilon v^{\prime}=0 \\
\varepsilon \Phi^{\prime \prime \prime}+c^{2}\left(\partial_{x} u^{\prime}+\partial_{y} v^{\prime}\right)=-(a / 2) P^{\prime}-(b / 2) T_{\mathrm{s}}^{\prime} .
\end{gathered}
$$

The variable $\Phi^{\prime \prime}$ is defined as $\Phi^{\prime \prime}=\left(\Phi^{\prime}+\Phi^{\prime \prime}\right) / 2$. The two terms on the right-hand side of Eq. (7c) correspond to the precipitation and temperature forcings. Equations $(7 \mathrm{a}-\mathrm{c})$ are the set of equations which will be used to study the response of the tropical atmosphere to deforestation.

\section{RESPONSE OF THE TROPICAL ATMOSPHERE TO DEFORESTATION OF THE AMAZON RAIN FOREST}

The response of the tropical atmosphere to deforestation will be studied, using the simple model developed in the previous section, on the assumption that deforestation is equivalent to introducing anomalies in the precipitation and surface temperature fields. Hence the model is being used to simulate the linear response of the tropical atmosphere to the forcing induced by changes in the precipitation and surface temperature fields, the magnitudes of which have been estimated from the GCM experiments.

Table 2 shows the magnitudes of the forcing terms corresponding to the predicted changes in surface temperature and precipitation. It also shows the total forcing due to deforestation. It is important to emphasize that the total forcing is the resultant of two competing processes: the positive surface temperature anomaly, which favours a converging flow, and the negative precipitation anomaly, which favours a diverging flow. The convergence of atmospheric moisture towards the deforested area is measured by the difference between precipitation and evaporation. The anomalies in convergence of atmospheric moisture (run-off) predicted by the GCM experiments are given in Table 1. Comparison of the signs and magnitudes of these anomalies and the signs and magnitudes of the deforestation forcing, from Table 2, indicates consistency of the model's results with our simple analysis. The consistency of our analysis, using a simple model, with the results of the more complicated GCM experiments suggests that the processes included 
TABLE 2. ESTIMATES OF THE FORCINGS DUE TO PREDICTED CHANGES IN SURFACE TEMPERATURE, PRECIPITATION AND DEFORESTATION IN THE AMAZON BASIN

\begin{tabular}{lccc}
\hline & $\begin{array}{c}\text { Dickinson and } \\
\text { Henderson-Sellers } \\
(1988)\end{array}$ & $\begin{array}{c}\text { Lean and } \\
\text { Warrilow } \\
(1989)\end{array}$ & $\begin{array}{c}\text { Nobre } \\
\text { et al. } \\
(1991)\end{array}$ \\
\hline Temperature forcing $\left(\mathrm{W} \mathrm{m}^{2}\right)$ & +0.7 & +1.1 & +1.2 \\
Precipitation forcing $\left(\mathrm{W} \mathrm{m}^{-2}\right)$ & -0.6 & -2.8 & -3.7 \\
$\begin{array}{l}\text { Precipitation and temperature } \\
\text { (deforestation) forcing }\left(\mathrm{W} \mathrm{m}^{-2}\right)\end{array}$ & +0.1 & -1.7 & -2.5 \\
\hline
\end{tabular}

In estimating these forcings the following typical values are used: $p=\Delta p=500 \mathrm{mb} ; \delta=$ $300 \mathrm{mb} ; H_{0}=3 \mathrm{~km}, \varepsilon=(2 \mathrm{~d}){ }^{1}$.

in the simple model are the dominant processes relevant to the deforestation problem. The relative magnitudes of the forcings due to surface temperature and to precipitation provide some idea about the relative importance of the two mechanisms in determining the total response. It would appear that the two forcings are of the same order of magnitude (see Table 2).

The set of equations $(7 \mathrm{a}-\mathrm{c})$ can be solved analytically for simple forms of the forcing function. We assume that the forcings due to surface temperature and precipitation anomalies have the forms

$$
F \begin{cases}=F_{0} \cos (k x)(1-y) \exp \left(-\frac{y^{2}}{4}\right) & (|x|<L) \\ =0 & (|x|>L)\end{cases}
$$

where $x$ and $y$ are distances in the zonal and meridional directions, respectively, both normalized by the equatorial Rossby radius $(c / 2 \beta)^{1 / 2}, \quad\left(\beta=\partial f /\left.\partial y\right|_{y=0}, \quad \beta=\right.$ $2.3 \times 10^{-11} \mathrm{~m}^{-1} \mathrm{~s}^{-1}$ ); for the set of parameters used in this study the Rossby radius is about $6^{\circ}$ latitude. $F_{0}$ is the magnitude of the forcing at the centre point, which is taken to be at the intersection of the equator and longitude $60^{\circ} \mathrm{W}$. It is assumed that $F_{0}=$ $\left\{(a / 2) P^{\prime}+(b / 2) T_{\mathrm{s}}^{\prime}\right\} . L$ is taken to be $10^{\circ}$ latitude; $k=\pi / 2 L$. The forcing function is shown in Fig. 2.

The analytical solutions of Eqs. (7a-c) corresponding to the forcing of Eq. 8 are described in the Appendix. These solutions are the same as those given by Gill (1980). For each of the three GCM experiments, the value of $F_{0}$ was estimated from Table 2. Figures 3 and 4 show the boundary-layer circulations corresponding to the forcings estimated from the results of Nobre et al. (1991) and Dickinson and Henderson-Sellers (1988), respectively. (The results of Lean and Warrilow (1989) are very similar to those of Nobre et al. (1991), hence the circulations corresponding to their results are not shown). The anomalies in the circulation due to deforestation are obtained by superposition of the anomalies due to temperature and precipitation forcing. (In each of the two Figs. 3 and 4 , a different scale is used to represent the mass flux vector; hence the magnitudes of the circulations corresponding to the two figures are not comparable).

The objective in studying the analytical solutions of this simple model is to provide a qualitative comparison between the circulation anomalies induced by the two different forcings. The simulated responses of the linear model illustrate the competition that exists between the circulation anomalies induced by the changes in temperature and precipitation. In Fig. 3 it is seen that the converging circulation due to temperature has about half the strength of the diverging circulation due to precipitation; as a result the 




Figure 2. The forcing function of Eq. (8) with $F_{0}=1$ and $L=10^{\circ}$ latitude.

total circulation anomaly due to deforestation is significantly milder than that due to precipitation alone, while in Fig. 4, which corresponds to the results of Dickinson and Henderson-Sellers (1988), it is seen that the circulation anomalies due to the surface temperature and precipitation have equal magnitudes and opposite directions, so resulting in a negligible total circulation anomaly.

Lean and Warrilow (1989) carried out two additional experiments: first they simulated the response of the atmosphere to an increase in surface albedo, then, in a different experiment, they simulated the response of the atmosphere to a reduction in surface roughness; they also did a deforestation experiment which included both effects. The average regional climatic changes from the three experiments are shown in Table 3 . On the basis of these results they argue that the reduction in moisture flux convergence is due mainly to the increased surface albedo rather than to the change in roughness. These results can be interpreted in terms of the linear model, the forcings due to precipitation and to surface temperature being estimated for each of the three experiments (see Table 3). Increased surface albedo leads to a larger decrease in run-off because the corresponding surface temperature forcing is negative, although very small. Hence, in this case, both temperature and precipitation forcing result in diverging flow; this explains the large reduction in run-off. The relatively large and positive temperature forcing in the roughness experiment leads to a converging flow, resulting in a smaller reduction in run-off. These experiments illustrate our point that the competition between the precipitation and surface temperature forcing is important in determining the changes of moisture flux convergence.

The linear model of the tropical atmosphere involves many assumptions and simplifications. In addition to the simplifications mentioned in the previous section, advection by the flow of the basic state was neglected, likewise the effects of topography. Although these effects might be important, the model nevertheless does include those processes that are necessary to illustrate and compare the basic components of the response of the 


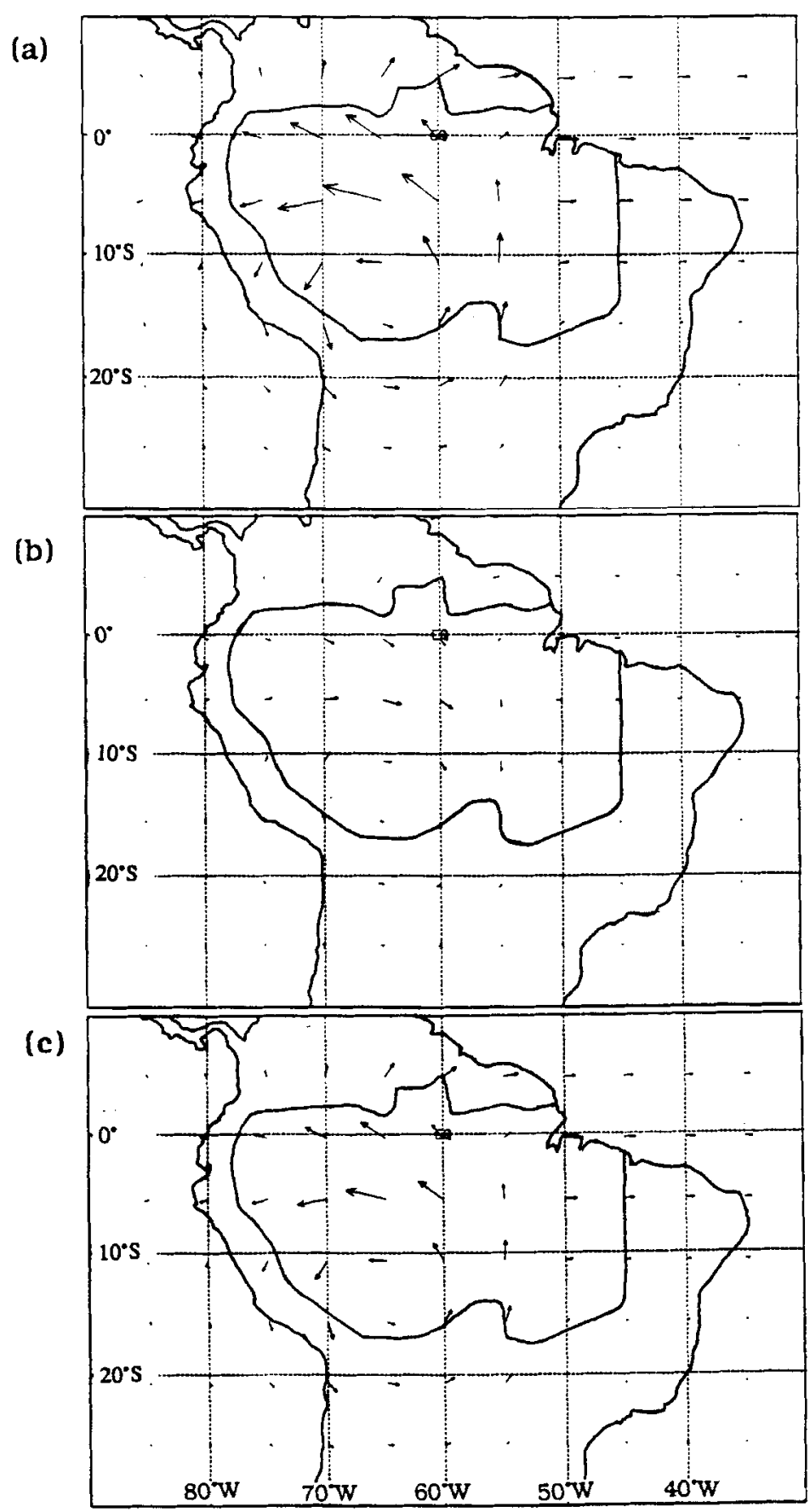

Figure 3. The boundary-layer circulation resulting from forcing the model with (a) precipitation forcing, (b) temperature forcing, (c) both precipitation and temperature. The vectors represent mass flux $\left(\mathrm{kg} \mathrm{m}^{-1} \mathrm{~s}^{-1}\right)$. The forcings are estimated from the results of Nobre et al. (1991). The maximum vector represents $1.7 \times 10^{4} \mathrm{~kg} \mathrm{~m}^{-1} \mathrm{~s}^{-1}$. 


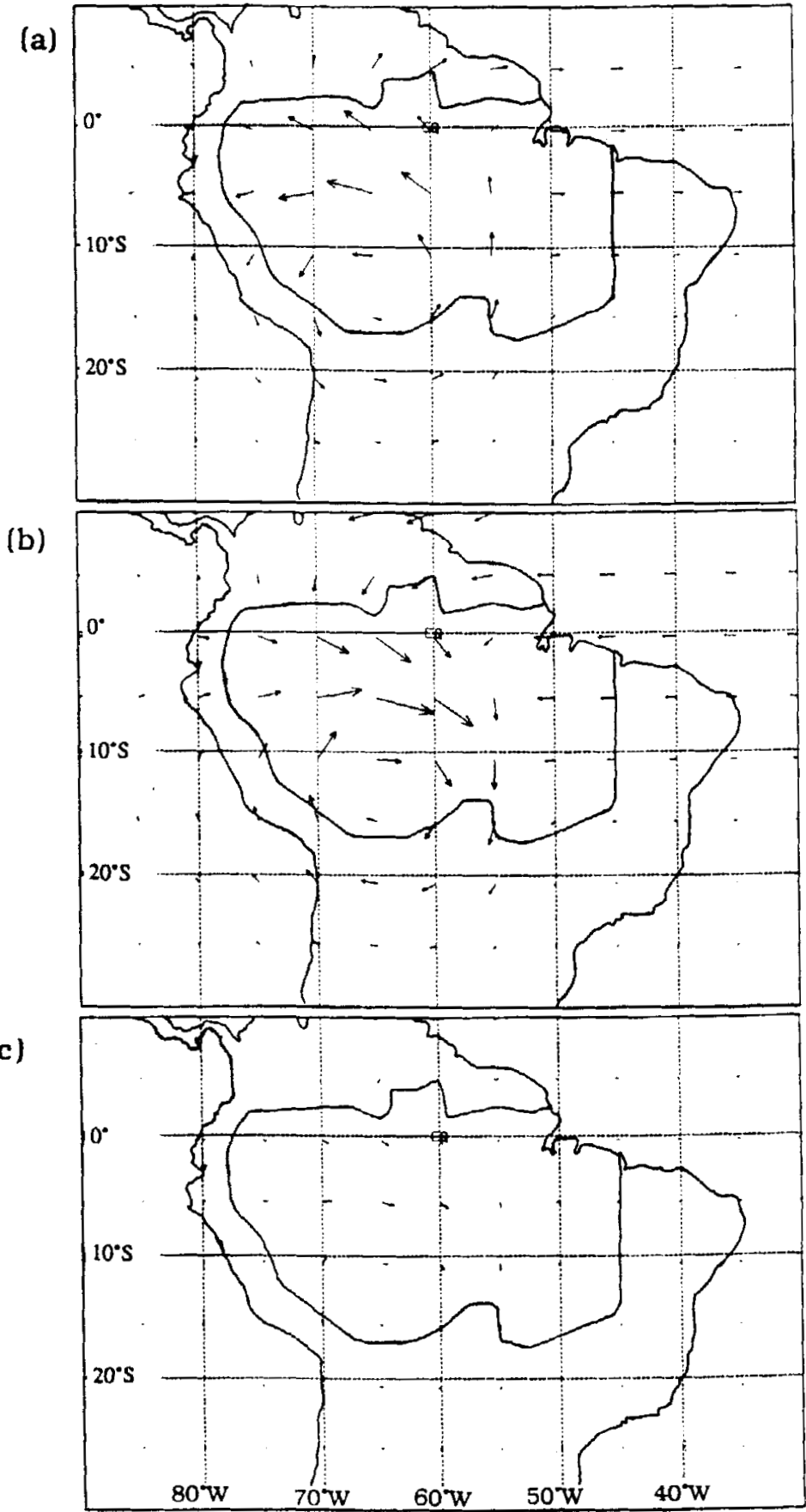

Figure 4. The boundary-layer circulation resulting from forcing the model with (a) precipitation forcing, (b) temperature forcing, (c) both precipitation and temperature. The vectors represent mass flux $\left(\mathrm{kg} \mathrm{m}^{-1} \mathrm{~s}^{-1}\right)$. The forcings are estimated from the results of Dickinson and Henderson-Sellers (1988). The maximum vector represents $0.4 \times 10^{4} \mathrm{~kg} \mathrm{~m}^{-1} \mathrm{~s}^{-1}$. 
TABLE 3. PREDICTIONS OF THE SPATIALLY AVERAGED REGIONAL CHANGES IN KEY ATMOSPHERIC VARIABLES AND THE CORRESPONDING FORCINGS, FROM THE EXPERIMENTS OF LEAN AND WARRILOW (1989)

\begin{tabular}{lccc}
\hline & $\begin{array}{c}\text { Increased } \\
\text { albedo }\end{array}$ & $\begin{array}{c}\text { Decreased } \\
\text { roughness }\end{array}$ & $\begin{array}{c}\text { Increased albedo and } \\
\text { decreased roughness }\end{array}$ \\
\hline Temperature $\left({ }^{\circ} \mathrm{C}\right)$ & -0.10 & +2.24 & +1.98 \\
Precipitation $\left(\mathrm{mm} \mathrm{d}^{-1}\right)$ & -0.75 & -0.69 & -1.34 \\
Evaporation $\left(\mathrm{mm} \mathrm{d}^{-1}\right)$ & -0.20 & -0.43 & -0.61 \\
Precipitation-evaporation $\left(\mathrm{mm} \mathrm{d}^{-1}\right)$ & -0.55 & -0.26 & -0.73 \\
Temperature forcing $\left(\mathrm{W} \mathrm{m}^{-2}\right)$ & -0.1 & +1.1 & +0.9 \\
Precipitation forcing $\left(\mathrm{W} \mathrm{m}^{-2}\right)$ & -1.6 & -1.4 & -2.8 \\
Precipitation + temperature forcing $\left(\mathrm{W} \mathrm{m}^{-2}\right)$ & -1.7 & -0.3 & -1.9 \\
\hline
\end{tabular}

tropical atmosphere to deforestation. A qualitative comparison of Fig. 1(d) with Fig. $3(\mathrm{c})$ shows that there is some similarity between the responses predicted by the GCM and by the linear model, particularly as regards the directions of the flux in the regions north-west, south-west and at the centre of the Amazon region. The differences between the two figures can be attributed to those nonlinear effects which were not considered in our analysis, and to the differences in the forms of the forcing functions in the GCM and the linear model. Note also that Fig. 1(d) shows the flow at $700 \mathrm{mb}$, while Fig. 3 (c) shows the mass flux averaged over the boundary layer.

\section{Sensitivity of Amazonian RUN-OFF to large-SCALE DEFORESTATION}

The simple linear model that we have presented can be used to study the sensitivity of Amazonian run-off to large-scale deforestation. It is assumed that the change in runoff from the region can be estimated from the difference between the anomaly in atmospheric moisture convergence in the boundary layer and the corresponding anomaly in atmospheric moisture divergence in the atmosphere above the boundary layer.

The change in convergence of the boundary-layer airmass, $\Delta C$, into a rectangular region covering the Amazon basin located between latitudes $5^{\circ} \mathrm{N}$ and $20^{\circ} \mathrm{S}$ and longitudes $45^{\circ} \mathrm{W}$ and $75^{\circ} \mathrm{W}$ was estimated. In estimating $\Delta C$, we used the solutions for $u^{\prime}$ and $v^{\prime}$ which are given in the Appendix, $\Delta C$ being considered as a linear function of $F_{0}$. The principle of conservation of mass requires that the change in divergence of airmass in the atmosphere above the boundary layer, $\Delta D$, should be equivalent to $\Delta \mathrm{C}$. Hence the change in run-off, $\Delta R$, is expressed as follows.

$$
\begin{aligned}
\Delta R & =r_{\mathrm{b}} \Delta C-r_{\mathrm{a}} \Delta D \\
& =\Delta C\left(r_{\mathrm{b}}-r_{\mathrm{a}}\right)
\end{aligned}
$$

where $r_{\mathrm{b}}$ and $r_{\mathrm{a}}$ are average mixing ratios in the boundary layer and in the atmosphere above the boundary layer, respectively. It is estimated that $\Delta R=0.19\left(r_{\mathrm{b}}-r_{\mathrm{a}}\right) F_{0}$, where $F_{0}$ is given by the following relation:

$$
F_{0}=(a / 2) P^{\prime}+(b / 2) T_{\mathrm{s}}
$$

and $\Delta R$ is in mm per day. Figure 5 shows the sensitivity of run-off as a function of the changes in precipitation and surface temperature. We have taken $r_{\mathrm{b}}=10 \mathrm{~g} \mathrm{~kg}^{-1}, r_{\mathrm{a}}=$ $4 \mathrm{~g} \mathrm{~kg}^{-1}$, and the run-off in the Amazon basin to be about $900 \mathrm{~mm}$ per year.

Figure 5 illustrates the competition between the two mechanisms, one driven by the changes in precipitation and the other by changes in surface temperature. Furthermore, the estimates in Fig. 5, which define the range of possible changes in run-off due to largescale deforestation, agree with the predictions from the climate models contained in 


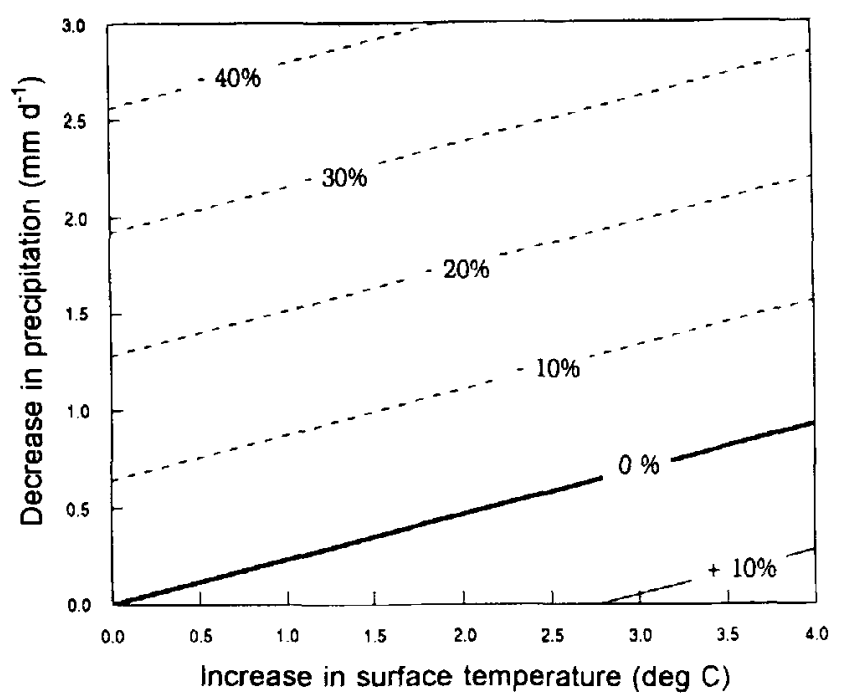

Figure 5. Sensitivity of Amazonian run-off to large-scale deforestation.

Table 1. Because of the simple structure of the model, the estimates of changes in runoff due to specific changes in precipitation and surface temperature may not represent accurate predictions.

\section{CONCLUSION}

The effect of deforestation of the Amazon rain forest on the boundary-layer circulation of the tropics has been approximated by the linear response of a simplified model of the tropical atmosphere to anomalies in surface temperature and precipitation. The magnitudes of these anomalies were estimated from the results of GCM experiments. All three experiments considered in this study indicate that deforestation will result in a positive change in surface temperature and a negative change in heating of the upper troposphere owing to a reduction in precipitation. While the temperature anomaly induces a circulation converging towards the Amazon region, the precipitation anomaly induces a diverging flow of similar strength. The two anomalies have opposite effects resulting in the circulation anomaly being smaller than the larger of the two components. Owing to the nature of the deforestation problem, i.e. a positive change in surface temperature combined with a negative change in precipitation, it is possible to have significant anomalies in surface temperature and precipitation with only a negligible effect on the circulation.

The dependence of the total response of the tropical atmosphere on the difference between the predicted strengths of surface temperature forcing and precipitation forcing suggests that the GCM predictions of circulation changes are highly sensitive. Given that climate models still need to be improved significantly to achieve reasonable accuracy in the description of important processes such as convection, radiation and land-surface processes, we should be cautious regarding the accuracy of their predictions. This is particularly relevant when the prediction depends on the opposition of two processes both of which are modelled with doubtful accuracy. Convection parametrizations and 
the descriptions of land-surface processes are among the least accurate in current GCMs and are in need of significant validation efforts (see Emanuel and Raymond 1992, and Henderson-Sellers and Dickinson 1992).

It is interesting to compare the EI Niño phenomenon with the deforestation problem. The former is the classical ocean-atmosphere interaction problem while the latter is the classical land-atmosphere interaction problem. The two problems are similar in the sense that in both cases the atmosphere responds to anomalies in the lower boundary conditions, specifically in evaporation and surface temperature. A positive precipitation (heating) anomaly usually follows the changes in surface temperature and evaporation. Observations indicate that during El Niño events all these anomalies occur at roughly the same locations, i.e. in phase with each other, which is likely to strengthen the overall effect on the tropical circulation. In contrast, the predictions of GCMs regarding the deforestation problem indicate that the changes in surface temperature and precipitation will have opposite signs. This difference in the sign of the predicted changes will probably weaken the overall effect on the tropical circulation.

The estimates of the forcing due to deforestation, which are given in Table 2, provide the means for comparing the forcing on the dynamics of the atmosphere due to deforestation with that due to the greenhouse effect. Raval and Ramanathan (1989) estimate that the forcing due to the greenhouse effect from doubling the carbon dioxide concentration is about $4 \mathrm{~W} \mathrm{~m}^{-2}$; from the results of our study we estimate that the forcing due to deforestation is of the order of a few $\mathrm{W} \mathrm{m}^{-2}$, from which it would seem that the forcing due to deforestation is of the same order of magnitude as the forcing due to the greenhouse effect from doubling the carbon dioxide concentration: one important difference is the localized nature of deforestation compared to the global extent of the greenhouse effect.

\section{ACKNOWLEDGEMENT}

We acknowledge the support of the National Aeronautics and Space Administration, NASA, (agreement NAG 5-1615). E. A. B. Eltahir is supported through a NASA graduate student fellowship (agreement NGT 30086). The views, opinions, and/or findings contained in this report are those of the authors and should not be construed as being an official NASA position, policy, or decision, unless so designated in other documentation.

\section{APPENDIX}

The following are expressions for the perturbations in the boundary-layer flux, and represent the solution of Eqs. (7a-c) corresponding to the forcing of Eq. (8). First, in the zonal direction,

$$
\begin{aligned}
u^{\prime}=F_{0} & {\left[\frac{-k\{1+\varepsilon \exp (-6 \varepsilon L)\} \exp 3 \varepsilon(x+L)}{2\left(k^{2}+9 \varepsilon^{2}\right)}\left(y^{2}-3\right)+\right.} \\
& \left.+\frac{k\{1+\exp (-10 \varepsilon L)\} \exp 5 \varepsilon(x+L)}{2\left(k^{2}+25 \varepsilon^{2}\right)}\left(y^{3}-6 y\right)\right] \exp \left(-\frac{y^{2}}{4}\right) \quad(x<-L)
\end{aligned}
$$




$$
\begin{aligned}
u^{\prime}=F_{0} & {\left[\frac{-\varepsilon \cos (k x)-k\{\sin (k x)+\exp \varepsilon(x+L)\}}{2\left(k^{2}+\varepsilon^{2}\right)} \exp \left(-\frac{y^{2}}{4}\right)-\right.} \\
& -F_{0}\left[\frac{3 \varepsilon \cos (k x)+k\{\sin (k x) \exp 3 \varepsilon(x-L)\}}{2\left(k^{2}+9 \varepsilon^{2}\right)}\left(y^{2}-3\right)\right] \exp \left(-\frac{y^{2}}{4}\right)+ \\
& +F_{0}\left[\frac{5 \varepsilon \cos (k x)+k\{\sin (k x)-\exp 5 \varepsilon(x-L)\}}{2\left(k^{2}+25 \varepsilon^{2}\right)}\left(y^{3}-6 y\right)\right] \exp \left(-\frac{y^{2}}{4}\right), \\
u^{\prime}= & F_{0}\left[\frac{-k\{1+\exp (-2 \varepsilon L) \exp \varepsilon(L-x)\}}{2\left(k^{2}+\varepsilon^{2}\right)} \exp \left(-\frac{y^{2}}{4}\right), \quad(|x|<L)\right.
\end{aligned}
$$

and in the meridional direction,

$$
\begin{aligned}
& v^{\prime}=F_{0}\left[\frac{-4 \varepsilon k\{1+\exp (-6 \varepsilon L)\} \exp 3 \varepsilon(x+L)}{\left(k^{2}+9 \varepsilon^{2}\right)} y+\right. \\
& \left.+\frac{6 \varepsilon k\{1+\exp (-10 \varepsilon L)\} \exp 5 \varepsilon(x+L)}{\left(k^{2}+25 \varepsilon^{2}\right)}\left(y^{2}-1\right)\right] \exp \left(-\frac{y^{2}}{4}\right) \quad(x<-L) \\
& v^{\prime}=F_{0}\left[\cos (k x)-\frac{12 \varepsilon^{2} \cos (k x)+k\{\sin (k x)-\exp 3 \varepsilon(x-L)\}}{\left(k^{2}+9 \varepsilon^{2}\right)}\right] y \exp \left(-\frac{y^{2}}{4}\right) \\
& +F_{0}\left[\frac{30 \varepsilon^{2} \cos (k x)+k\{\sin (k x)-\exp 5 \varepsilon(x-L)\}}{\left(k^{2}+25 \varepsilon^{2}\right)}\left(y^{2}-1\right)\right. \\
& \left.+\cos (k x) y^{2}\right] \exp \left(-\frac{y^{2}}{4}\right) \\
& (|x|<L) \\
& v^{\prime}=0 \\
& (x>L)
\end{aligned}
$$

For details of the derivation of these expressions refer to Gill (1980). In deriving these expressions, it is supposed that $2 \varepsilon k \ll 1$ and that the equations are solved using an equatorial $\beta$-plane approximation, $F_{0}$ is normalized using the equatorial Rossby radius as a length scale; the timescale is given by $(2 \beta c)^{-1 / 2}$. The resulting $u^{\prime}$ and $v^{\prime}$ are dimensionless.

Dickinson, R. E. and Henderson-Sellers, A.

Emanuel, K. A. and Raymond, D. J.

Gill, A. E.

Henderson-Sellers, A. and Dickinson, R. E,

Lean, J. and Warrilow, D. A.

Lindzen, R. S, and Nigam, S.

Matsuno, T.

\section{REFERENCES}

1988

1992

1980

1992

1989

1987

1966
Modelling tropical deforestation: A study of GCM land-surface parametrization. Q. J. R. Meteorol. Soc., 114, 439-462

Report from a workshop on cumulus parameterization. Bull Am. Meteorol. Soc., 73, (3), 318-326

Some simple solutions for heat-induced tropical circulation. Q. J.R. Meteorol. Soc., 106, 447-462

Inter-comparison of land-surface parameterizations launched. Trans. Am. Geophys. Union, EOS, 73, (17), 195-196

Simulation of the regional climatic impact of Amazon deforestation. Nature, 342, 411-413

On the role of sea surface temperature gradients in forcing low-level winds and convergence in the tropics. J. Atmos. Sci., 44, (17), 2418-2436

Ouasi-geostrophic motions in the equatorial area. J. Meteorol. Soc. Jpn. $44,25-43$ 
Neelin, J. D.

Nobre, C. A., Sellers, P. J. and Shukla, J.

Raval, A. and Ramanathan, V.

Zebiak, S. Z.
1988 A simple model for surface stress and low-level flow in the tropical atmosphere driven by prescribed heating $Q$. $J$. R. Meteorol. Soc., 114, 747-770

1989 On the interpretation of the Gill model. J. Atmos. Sci., 46, (15), 2466-2468

1991 Amazonian deforestation and regional climatic change. $J$. Climatol., 4, 957-988

1989 Observational determination of the greenhouse effect. Nature, $342,758-761$

1982 A simple atmospheric model of relevance to El Niño. J. Atmos. Sci. , 39, 2017-2027 